\title{
Endothelial growth factor receptor-mutant lung cancer and post-operative care management: one size does not fit all
}

\author{
Javeryah Safi ${ }^{1}$, Sarah W. Gordon ${ }^{2}$, Peter Lee ${ }^{1}$, Howard Li ${ }^{1}$, Patrick Nana-Sinkam ${ }^{1}$, Rachit D. Shah ${ }^{3}$, \\ Ray W. Shepherd ${ }^{1}$, Samira Shojaee ${ }^{1}$
}

${ }^{1}$ Department of Internal Medicine, Division of Pulmonary and Critical Care Medicine, Virginia Commonwealth University, Richmond, VA, USA; ${ }^{2}$ Department of Internal Medicine, Division of Hematology and Oncology, Virginia Commonwealth University, Richmond, VA, USA; ${ }^{3}$ Department of Surgery, Division of Cardiothoracic surgery, Virginia Commonwealth University, Richmond, VA, USA

Correspondence to: Samira Shojaee. Department of Internal Medicine, Division of Pulmonary and Critical Care Medicine, Virginia Commonwealth University, Richmond, VA, USA. Email: sshojaee@mcvh-vcu.edu.

Comment on: Liang W, Cai K, Chen C, et al. Society for Translational Medicine consensus on postoperative management of EGFR-mutant lung cancer (2019 edition). Transl Lung Cancer Res 2019;8:1163-73.

Submitted Jun 01, 2020. Accepted for publication Jun 24, 2020.

doi: $10.21037 / \mathrm{atm}-20-4408$

View this article at: http://dx.doi.org/10.21037/atm-20-4408

Lung cancer remains the leading cause of cancer related deaths globally (1). Non-small cell lung cancer (NSCLC) accounts for nearly $85 \%$ of all lung cancers. The slow progressive decline in both the incidence and mortality from lung cancer in the United States since 2005 is mainly attributable to decreased rates of smoking (2). However, such a trend is yet to be seen worldwide. At the time of diagnosis, $79 \%$ of patients present with evidence of regional or distant spread. Overall 5-year survival remains low at $19.4 \%(3,4)$. Thus, there are ongoing efforts internationally to improve these outcomes through early detection and screening for lung cancer along with advances in chemotherapy, immunotherapy, stereotactic radiation therapy and targeted therapies (5-7).

Despite the new developments in novel targeted therapies, the cornerstone of lung cancer management remains focused on prevention and early detection for optimal outcomes. When diagnosed early, surgical resection is a highly desirable option for patients who can undergo surgery. However, there is significant variability and controversy in rates of recurrence following curative intent surgery for early stage NSCLC. Risk of recurrence is influenced by the type of resection (increased risk in sub lobar and wedge resections compared to lobectomy), histologic subtype, and pathologic stage (5-19\% in Stage I, $11-27 \%$ in Stage II, and $24-40 \%$ in Stage IIIA) (8-10). Neoadjuvant chemotherapy has been shown to improve overall survival, although there is no consistent evidence that it can improve local control.

Importantly, $10-15 \%$ of all patients with NSCLC carry an endothelial growth factor receptor (EGFR) mutation, with varying rates based on gender, race, and smoking status (11). Several mutations in EGFR have been identified (exon 19 deletion, p.L858R point mutation in exon 21) which are responsive to tyrosine kinase inhibitors (TKI's) (12). There are several generations of EGFRTKI inhibitors, including Erlotinib and Gefitinib (first generation), Afatinib (second generation) and Osimertinib (third generation).

Published guidelines by American College of Chest Physicians (ACCP) and National Comprehensive Cancer Network (NCCN) updated in 2020 recommend that postresection margins and pathological stage should inform decisions to administer adjuvant therapies $(13,14)$. The mainstay of adjuvant therapy in NSCLC remains traditional platinum-based chemotherapy. Currently, EGFR targeted therapy is only considered the standard of care for patients with advanced stage lung cancer. In patients with advanced NSCLC, EGFR-TKIs have shown improved progression free survival compared to systemic chemotherapy, with a favorable toxicity profile (15-19). In a recently published trial by FLAURA investigators, Osimertinib was shown to have improved overall survival compared to earlier generation TKIs (20). Thus, there is an increasing appeal 
to use TKI's as first line agents in advanced NSCLC. However, the role of EGFR-TKI in post-operative EGFR mutant NSCLC is unclear.

The care of a patient with lung cancer is optimally achieved in a multidisciplinary fashion and involves challenging decisions and significant uncertainty while relying on the scientific literature, available resources and experiences, and each individual patient preference.

According to the National Academy of Sciences, clinical practice guidelines are "statements that include recommendations intended to assist practitioners and patient decisions to optimize patient care for specific clinical circumstances" (21). Guidelines are developed through strategic and systematic review of available evidence and should assess the benefits and harms of each intervention and of alternative options. Guidelines are developed by a multidisciplinary team of carefully selected experts and enlist specific interventions to be compared with alternative strategies among a pre-specified population of patients, leading to a measurable outcome of interest. Traditionally, a consensus statement is developed when lack of significant evidence precludes the possibility of arriving at evidence-based recommendations, hence the need for expert panel survey, often achieved through a modified Delphi method (22), leading to a list of suggestions instead of recommendations. As with any other research, when guidelines are developed without adequate rigor in methodology, they can lead to inaccurate and potentially harmful results represented in the form of statements and recommendations.

In this issue of the journal, Liang and colleagues developed a consensus statement based on a review of the literature, to guide the post-operative management of patients with EGFR-positive NSCLC (23). As a significant percentage of patients undergoing surgical resection, especially with large tumors and nodal involvement will experience recurrence of the disease, the authors in collaboration with multi-disciplinary experts from China and worldwide, have sought to address the existing gaps in the postoperative management of these patients by consolidating the available evidence. There are eight consensus statements presented by the panel members. Each of the statements earned a strong recommendation by the panelists and was supported with a minimum category level of evidence and consensus of $2 \mathrm{~B}$ or greater. The strength of each consensus statement was rated using the Grading of Recommendations, Assessment, Development and Evaluation (GRADE) system (24).
The authors should be congratulated on their efforts to develop an evidence-based guideline and their use of a multidisciplinary team of surgeons, oncologists, and pulmonologists. While the authors conducted a thoughtful review of the current literature on the use of TKI's in EFGR-mutant positive NSCLC, there are significant limitations in their process for guideline development. Important aspects of methodology and consensus development deserve further attention. Details on expert panelist selection, questions and systematic search strategy development, study selection, evidence assessment, and methods used for achieving consensus are not reported. The GRADE system relies on four elements to assess the quality of evidence (study design, study quality, consistency, and directness) and specific elements to determine strength of a recommendation (balance of harm $v s$. benefit, quality of evidence, certainty of baseline risk and translation of evidence to specific clinical circumstances) (24). The authors fail to provide a systematic assessment of each included study as data is pooled from different studies containing heterogeneous populations. Inability to control for heterogeneity can leave an analysis vulnerable to bias and inaccuracy in effect estimates (statements and recommendations) due to varying definitions for treatment, time to therapy, cancer stage, histology, and other population-based heterogeneity.

Additionally, it is unclear if the recommendations constitute portions of a guideline or consensus statement. Liang et al. report their results in a guideline format with graded recommendations. However, they refer to the process as a consensus statement without clear details on methods to achieve consensus or develop guideline recommendations.

The aforementioned challenges become increasingly evident as the authors present their data. The opinions of additional multidisciplinary experts following the consensus statements, often differ and highlight the difficulties faced in constructing these statements. The authors recommend routine testing for EGFR mutation in all surgically resected specimens of NSCLC, with no distinction of the pathological stage post operatively. Testing for EGFR mutations in stage I NSCLC is only necessary if the intention is to give EGFR TKIs as adjuvant therapy at the time of recurrence. The authors also recommend the use of EGFR-TKIs as one of the options for adjuvant treatment in operable stage II-III NSCLC. In the absence of overall survival data for adjuvant EGFR-TKI use, it would be premature to make these recommendations, especially in 
resource limited health care environments. Pooling evidence from multiple studies with heterogeneous populations, without clear description of the populations for each recommendation, can lead to inaccurate estimates that may not be generalizable to all stages of EGFR-mutant NSCLC. The authors also propose utilizing prediction models to identify high risk stage 1 patients for adjuvant EGFR-TKI therapy. Although several biomarkers have been identified and prediction models created, their role remains limited to clinical trials in the absence of available favorable impact data (25-27). They recommend continuing EGFR-TKI therapy for 2 years, although they note that the studies included in the consensus paper have varying durations of EGFR-TKI use and cite studies on breast cancer to draw parallel conclusions for the duration of EGFR-TKI therapy. However, the optimal duration of EGFR-TKIs in adjuvant therapy remains unclear as currently, EGFRTKI duration in advanced metastatic lung cancer relies on disease progression (14). The authors rightly identify that the studies utilized in creating the statements primarily rely on data from a Chinese population, which limits its generalizability to wider populations $(16,28,29)$. While the impact on overall survival is being explored in ongoing studies in the USA, China and Japan, new evidence may aid in the development of future guidelines to help clinicians care for patients with EGFR-mutant NSCLC who undergo surgery (30-32).

Clinical guidelines and consensus statements are only one method for improving evidence-based quality patient care and their utilization should be prioritized for patients in whom a clear treatment path is not defined. Clinicians should strive for multidisciplinary and personalized care in a patient with lung cancer and use guidelines judiciously.

\section{Acknowledgments}

Funding: None.

\section{Footnote}

Provenance and Peer Review: This article was commissioned by the editorial office, Annals of Translational Medicine. The article did not undergo external peer review.

Conflicts of Interest: The authors have completed the ICMJE uniform disclosure form (available at http://dx.doi. org/10.21037/atm-20-4408). RWS reports grants from Olympus/SPIRATION, consulting fees from COOK, royalties for authorship rom UpToDAte, outside the submitted work. The other authors have no conflicts of interests to declare.

Ethical Statement: The authors are accountable for all aspects of the work in ensuring that questions related to the accuracy or integrity of any part of the work are appropriately investigated and resolved.

Open Access Statement: This is an Open Access article distributed in accordance with the Creative Commons Attribution-NonCommercial-NoDerivs 4.0 International License (CC BY-NC-ND 4.0), which permits the noncommercial replication and distribution of the article with the strict proviso that no changes or edits are made and the original work is properly cited (including links to both the formal publication through the relevant DOI and the license). See: https://creativecommons.org/licenses/by-nc-nd/4.0/.

\section{References}

1. Bray F, Ferlay J, Soerjomataram I, et al. Global Cancer Statistics 2018; GLOBOCAN Estimates of Incidence and Mortality Worldwide for 36 Cancers in 185 Countries. CA Cancer J Clin 2018;68:394-424.

2. Henley SJ, Thomas CC, Lewis DR, et al. Annual report to the nation on the status of cancer, part II: Progress toward Healthy People 2020 objectives for 4 common cancers. Cancer 2020;126:2250-66.

3. Travis WD, Brambilla E, Nicholson AG, et al. The 2015 World Health Organization Classification of Lung Tumors: Impact of Genetic, Clinical and Radiologic Advances Since the 2004 Classification. J Thorac Oncol 2015;10:1243-60.

4. Tsao AS, Scagliotti GV, Bunn PA Jr, et al. Scientific Advances in Lung Cancer 2015. J Thorac Oncol 2016;11:613-38.

5. Forde PM, Ettinger DS. Targeted therapy for non-smallcell lung cancer: past, present and future. Expert Rev Anticancer Ther 2013;13:745-58.

6. Li T, Kung HJ, Mack PC, et al. Genotyping and genomic profiling of non-small-cell lung cancer: implications for current and future therapies. J Clin Oncol 2013;31:1039-49.

7. Shojaee S, Nana-Sinkam P. Recent advances in the management of non-small cell lung cancer. F1000Res 2017;6:2110.

8. Kelsey CR, Marks LB, Hollis D, et al. Local recurrence 
after surgery for early stage lung cancer: an 11-year experience with 975 patients. Cancer 2009;115:5218-27.

9. Wang C, Wu Y, Shao J, et al. Clinicopathological variables influencing overall survival, recurrence and postrecurrence survival in resected stage I non-small-cell lung cancer. BMC Cancer 2020;20:150.

10. Mahvi DA, Liu R, Grinstaff MW, et al. Local Cancer Recurrence: The Realities, Challenges, and Opportunities for New Therapies. CA Cancer J Clin 2018;68:488-505.

11. Shi Y, Au JS, Thongprasert S, et al. A prospective, molecular epidemiology study of EGFR mutations in Asian patients with advanced non-small-cell lung cancer of adenocarcinoma histology (PIONEER). J Thorac Oncol 2014;9:154-62.

12. Kobayashi S, Canepa HM, Bailey AS, et al. Compound EGFR mutations and response to EGFR tyrosine kinase inhibitors. J Thorac Oncol 2013;8:45-51.

13. Donington J, Ferguson M, Mazzone P, et al. American College of Chest Physicians and Society of Thoracic Surgeons consensus statement for evaluation and management for high-risk patients with stage I non-small cell lung cancer. Chest 2012;142:1620-35.

14. National Comprehensive Cancer Network. NonSmall Cell Lung Cancer (Version 3.2020). Accessed April 16, 2020. Available online: https://www.nccn.org/ professionals/physician_gls/pdf/nscl.pdf

15. Mok TS, Wu YL, Thongprasert S, et al. Gefitinib or carboplatin-paclitaxel in pulmonary adenocarcinoma. $\mathrm{N}$ Engl J Med 2009;361:947-57.

16. Zhong WZ, Wang Q, Mao WM, et al. Gefitinib versus vinorelbine plus cisplatin as adjuvant treatment for stage II-IIIA (N1-N2) EGFR-mutant NSCLC (ADJUVANT/ CTONG1104): a randomised, open-label, phase 3 study. Lancet Oncol 2018;19:139-48.

17. Kelly K, Altorki NK, Eberhardt WE, et al. Adjuvant Erlotinib Versus Placebo in Patients With Stage IBIIIA Non-Small-Cell Lung Cancer (RADIANT): A Randomized, Double-Blind, Phase III Trial. J Clin Oncol 2015;33:4007-14.

18. Rosell R, Carcereny E, Gervais R, et al. Erlotinib versus standard chemotherapy as first-line treatment for European patients with advanced EGFR mutation-positive non-small-cell lung cancer (EURTAC): a multicentre, open-label, randomised phase 3 trial. Lancet Oncol 2012;13:239-46.

19. Sequist LV, Yang JC, Yamamoto N, et al. Phase III study of afatinib or cisplatin plus pemetrexed in patients with metastatic lung adenocarcinoma with EGFR mutations. J
Clin Oncol 2013;31:3327-34.

20. Ramalingam SS, Vansteenkiste J, Planchard D, et al. Overall Survival with Osimertinib in Untreated, EGFR-Mutated Advanced NSCLC. N Engl J Med 2020;382:41-50.

21. Graham R, Mancher M, Wliman DM, et al. editors. Clinical Practice Guidelines We Can Trust. Washington: The National Academies Press, 2011.

22. Custer R, Scarcella J et al. The Modified Delphi Technique - A Rotational Modification. JCTE 1999;15:50-8.

23. Liang W, Cai K, Chen C, et al. Society for Translational Medicine consensus on postoperative management of EGFR-mutant lung cancer (2019 edition). Transl Lung Cancer Res 2019;8:1163-73.

24. Jaeschke R, Guyatt GH, Dellinger P, et al. Use of GRADE grid to reach decisions on clinical practice guidelines when consensus is elusive. BMJ 2008;337:a744.

25. Carnio S, Novello S, Papotti M, et al. Prognostic and predictive biomarkers in early stage non-small cell lung cancer: tumor based approaches including gene signatures. Transl Lung Cancer Res 2013;2:372-81.

26. Bergot E, Levallet G, Campbell K, et al. Predictive biomarkers in patients with resected non-small cell lung cancer treated with perioperative chemotherapy. Eur Respir Rev 2013;22:565-76.

27. Wallerek S, Sørensen JB. Biomarkers for efficacy of adjuvant chemotherapy following complete resection in NSCLC stages I-IIIA. Eur Respir Rev 2015;24:340-55.

28. Pennell NA, Neal JW, Chaft JE, et al. SELECT: A Phase II Trial of Adjuvant Erlotinib in Patients With Resected Epidermal Growth Factor Receptor-Mutant Non-SmallCell Lung Cancer. J Clin Oncol 2019;37:97-104.

29. Yue D, Xu S, Wang Q, et al. Erlotinib versus vinorelbine plus cisplatin as adjuvant therapy in Chinese patients with stage IIIA EGFR mutation-positive non-small-cell lung cancer (EVAN): a randomised, open-label, phase 2 trial. Lancet Respir Med 2018;6:863-73.

30. National Cancer Institute (NCI). Genetic Testing in Screening Patients with Stage IB-IIIA Non-small Cell Lung Cancer That Has Been or Will Be Removed by Surgery (The ALCHEMIST Screening Trial). Available online: https://clinicaltrials.gov/ct2/show/ NCT02 194738

31. AstraZeneca. AZD9291 Versus Placebo in Patients With Stage IB-IIIA Non-small Cell Lung Carcinoma, Following Complete Tumor Resection With or Without Adjuvant Chemotherapy. (ADAURA). Available online: https:// 
clinicaltrials.gov/ct2/show/NCT02511106?term=Japan+E GFR+adjuvant

32. Betta Pharmaceuticals Co., Ltd. Icotinib versus Placebo as Adjuvant Therapy in EGFR-mutant Lung

Cite this article as: Safi J, Gordon SW, Lee P, Li H, Nana-Sinkam P, Shah RD, Shepherd RW, Shojaee S. Endothelial growth factor receptor-mutant lung cancer and post-operative care management: one size does not fit all. Ann Transl Med 2020;8(24):1697. doi: 10.21037/atm-20-4408
Adenocarcinoma (ICWIP). Available online: https:// clinicaltrials.gov/ct2/show/NCT02125240?term=Japan+E GFR+adjuvant 